\title{
SOBRE A INCERTEZA
}

Ivo Assad IBRI ${ }^{1}$

- RESUMO: Este artigo expõe elementos da doutrina epistemológica de Charles S. Peirce (1839-1914), denominada Falibilismo. Procura-se evidenciar como tal doutrina se desenvolve do interior de teorias metafísicas do autor, a exemplo de seu Evolucionismo e da estrutura categorial da Realidade, formando um dueto com sua concepção ontológica de Acaso. Em verdade, o Falibilismo configurar-se-á como a doutrina que é conseqüência do indeterminismo de dupla face de Peirce, a saber, simultaneamente ontológico e epistemológico.

- PALAVRAS-CHAVE: Peirce; epistemologia; metafísica; acaso.

\section{Introdução}

O título deste artigo, não deve ter escapado a ninguém, parodia a famosa obra de final de vida de Wittgenstein. Contudo, não discorreremos sobre este autor. O tema versa sobre a doutrina do Falibilismo do filósofo norte-americano Charles S. Peirce (1839-1914). ${ }^{2}$ Tal doutrina afirma ser nosso conhecimento essencialmente falível, não meramente pela veracidade da máxima errare humanum est, mas, também, por toda uma construção de mundo que reconhece um princípio de Acaso ontológico atuante na Natureza. Evidentemente requer-se, então, um concomitante desenvolvimento, no interior da Filosofia peirceana, de dois terre-

\footnotetext{
1 Departamento de Filosofia - Pontifícia Universidade Católica - São Paulo - SP.

2 Confira-se, a propósito, um interessante artigo de Johanson (1994), que procura estabelecer paralelos entre os conceitos de certeza dos dois autores.
} 
nos de investigação: a Epistemologia, âmbito próprio do Falibilismo, e a Metafísica, enquanto construção de uma teoria do Real.

\section{Acaso e incerteza}

\section{Em 1897, Peirce enunciou:}

Todo raciocínio positivo é da natureza de julgar a proporção de alguma coisa em relação ao todo de uma coleção pela proporção encontrada em uma amostra. Assim, há três coisas que nunca devemos esperar através do raciocínio, a saber: certeza absoluta, exatidão absoluta e universalidade absoluta. (1931-1974, v.1, § 141)

Evidentemente, aqui, Peirce se refere à figura do conhecimento indutivo, que, no ver do autor, possui um imbricamento lógico com duas outras formas de argumento, quais sejam, a abdução e a dedução. Ainda segundo o autor, a abdução é o processo de formação de uma hipótese, que detém a exclusividade heurística do conhecimento: toda nova informação científica advém desta forma lógica.

Um dos pontos mais originais de sua obra, a $a b d u c ̧ \tilde{a} o^{3}$ configura a importância que Peirce atribuiu a argumentos do tipo conjecturais. De acordo com ele, é extraordinário como o espírito humano detém uma espécie de disposição para a verdade 4 cujos fundamentos passam, também, por sua cosmologia e, principalmente, pelo seu Realismo e Idealismo Objetivo de extração schellinguiana. ${ }^{5}$

A figura da dedução, de seu lado, cumpre o papel de obter da hipótese, uma vez abdutivamente formada, conseqüências logicamente necessárias, observáveis experiencialmente por indução. Ora, se a verificação da veracidade da hipótese depende exclusivamente da indução, e esta, no ver do autor, nunca conduz à certeza absoluta, todo o corpo da ciência, onde progressivamente são incorporadas novas teorias, convive com um certo grau de incerteza que, não obstante, não a torna inoperativa. Muito pelo contrário, as ciências da natureza, é fato de reconheci-

3 Há diversos estudos interessantes sobre a abdução em Peirce. Uma abordagem que tem em conta o realismo do autor pode ser conferida em Graybosh (1993).

4 Esta expressão é nossa e não do autor.

5 Cumpre aqui apenas comentar que a metafísica de Schelling foi altamente inspiradora na construção da cosmologia peirceana. 
mento universal, têm evoluído continuamente mesmo carecendo de certeza absoluta no seu sistema de representação das leis da natureza, malgrado períodos históricos conhecidos de estagnação, não debitáveis exclusivamente ao método da ciência.

Surgem, aqui, três questões atinentes, de um viés, com a validade mesma da indução como instância última de legitimação de uma teoria e, por outro, com a significação dos conceitos de veracidade e leis da natureza, anteriormente utilizados.

Em verdade, a legitimação da indução, na Filosofia peirceana, depende, fundamentalmente, de uma complexa discussão sobre a validade ontológica do conceito de lei. No que respeita ao conceito de verda$d e$, não menos complexo que o de lei, carece-se, pelo menos, do desenvolvimento da idéia de Evolucionismo presente no sistema do autor. Este imbricamento íntimo de diversas teorias torna o termo sistema legitimamente utilizável quando se refere ao corpo teórico que constitui a Filosofia de Peirce.

Tratemos, de início, do conceito de lei. Aqui, Peirce vai buscar, como raiz de suas idéias, a querela dos universais presente na antiga escolástica, tendo por paradigma inicial o realismo de Duns Scotus. À questão geral daquela época - "são os universais reais?" - Peirce propõe sua equivalente contemporânea: "são reais as leis da natureza ou meras ficções da mente?". Por adotar uma resposta positiva a esta questão, o autor se declara realista e se afasta de uma tradição nominalista de Filosofia que, se não adota a sua negativa, pelo menos a supõe indecidível, como boa herança do ceticismo de Hume.

Este traço realista de Peirce, a nosso ver, faz toda a diferença no entendimento de suas posições filosóficas e, de certo modo, não tem sido devidamente considerado por muitos comentaristas de sua obra. Segundo o autor, é a suposição da realidade das leis que permite o entendimento da função preditiva das teorias; elas requerem um correlato ontológico dotado de um esse in futuro que justifique o sucesso das predições científicas e a correlata legitimidade da indução. Não obstante, este requerer enseja, como coerência teórica necessária, uma hipótese cuja plausibilidade é extremamente forte, e nunca uma certeza dedutivamente necessária.

Já na maturidade de seu pensamento, Peirce torna-se cada vez mais radicalmente realista. Seu estudo da Lógica dos Relativos e da Teoria do Continuum o faz modificar aquela questão para "há quaisquer continua reais?", negando seu anterior arquétipo de realismo, Duns Scotus, pela transformação de um realismo de gêneros em um realismo de sistemas. 
Peirce vai, também, emprestar a significação de uma palavra de invenção de Scotus - realitas - definindo realidade como "aquilo que permanece não afetado pelos nossos modos de representá-lo" (1931-1974, v.5, § 565), num reconhecimento explícito da alteridade que permeia tudo o que se possa considerar Real. É da escolástica, também, que Peirce traz para a contemporaneidade a distinção entre realidade e existência, com esta sendo o locus do individual e, aquela, a expressão ontológica da generalidade dos continua. Dessa distinção, Peirce extrai duas de suas categorias, inicialmente fundadas fenomenologicamente, quais sejam, terceiridade, o modo de ser real da generalidade da Lei, e segundidade, o modo de ser real do individual ou particular como concreção da generalidade ontológica. Completa suas categorias, numa tríade, a primeiridade, que subsume, metafisicamente, o modo de ser do incondicionado, daquilo que, fenomenologicamente, aparece como diversidade, assimetria e espontaneidade na Natureza, e que, na sua condição genética de liberdade, contradita o modo de ser da lei, fundado na uniformidade, na ordem e na simetria.

Dispondo desses três modos de ser como estruturadores do Mundo ou, semioticamente falando, do Objeto em sua realidade, Peirce funda sua doutrina do Falibilismo, agora não tão-somente ancorada na proverbialidade de nossos humanos erros, mas, também, num grau de indeterminação do Objeto, submetido, por um lado, à ordem da lei que permite que a representação tenha um poder preditivo, não obstante falivel, e, de outro, à aleatoriedade do Acaso, como um princípio ontológico responsável pelos desvios em relação à ordem.

Nosso conhecimento do mundo é, por esta razão, revestido de uma incerteza composta por duas instâncias de erraticidade, quais sejam, a da representação e a do objeto representado. Tal erraticidade não irá, todavia, impedir o crescimento e o aperfeiçoamento de nosso humano conhecer.

Esses quesitos de crescimento e aperfeiçoamento sugerem, no nível epistemológico, a idéia de que nosso sistema de signos encontra-se em evolução, fato, aliás, historicamente incontestável: nosso conhecimento da Natureza é hoje extraordinariamente mais amplo e detalhado que em qualquer momento do passado. Estaria, contudo, o objeto também em evolução?

\section{Evolucionismo e a origem das leis}

À pergunta anterior, a resposta peirceana é também positiva. Estudioso das teorias de Spencer, Lamarck e Darwin, e convivendo no século 
XIX com o clima intelectual do evolucionismo, Peirce conduz sua Filosofia cada vez mais por caminhos genealógicos, construindo uma Filosofia Genética, como, a propósito, defendia Schelling, por quem o autor nutria grande admiração. ${ }^{6}$

Longe de quaisquer dogmatismos, sua metafísica confinada, após Kant, ao universo da experiência possível, procura sempre erigir hipóteses de origem, resgatando o antigo modo grego de se fazer filosofia, em busca da Arché.

É, assim, que Peirce (1931-1974, v.7, § 512-4) poderá receber dentro de seu sistema a questão: “Qual a origem das leis da natureza?". Evidentemente, numa sã metafísica, não caberia uma resposta que conjectura sobre um mundo ordenado e pronto como obra de alguma divindade. Também, afirmar a incognoscibilidade como resposta, segundo o autor, conduz, de um lado, ao espectro da coisa em si, banido da filosofia peirceana como elemento herético, conforme se comentará adiante e, de outro, constitui postura contraditória em si mesma, pois, como hipótese, desfaz, de princípio, sua função precípua que é explicar.

Por conseguinte, Peirce é levado a adotar uma hipótese evolucionista para as leis da natureza, afirmando que elas se formaram a partir de um estado de coisas em que não havia quaisquer modos de ordenação dos individuais: um mundo regido pelo cego Acaso. Esta idéia não tem originalidade de per si, uma vez estar presente na Cosmologia dos antigos gregos. Todavia, são absolutamente novas as conseqüências que dela Peirce extrai, a exemplo de:

a) admitir o universo sob evolução e a formação das leis como uma natural tendência à ordem a partir do acaso, conduz à conclusão de que aquelas leis não se encontram em nenhum ponto final definido. Observamos, de fato, um mundo apenas parcialmente ordenado, onde a diversidade cresce por ação do acaso. Convivem, portanto, acaso e lei na constituição da existência ou, sob as categorias peirceanas, é permissível dizer que os modos de ser da primeiridade e da terceiridade confluem para o modo de ser da segundidade.

b) por que, contudo, se formam as leis? Não restando dúvidas sobre o fato de que elas se formaram, uma vez podermos agora delas falar, Peirce irá considerar que as leis são hábitos de conduta da Natureza, e sua formação se dá por uma tendência do universo de adquirir hábitos que, segundo

6 Curiosamente, a literatura filosófica não registra pesquisas de fôlego sobre a relação entre estes autores. Mencione-se, contudo, Esposito (1977, 1980); este autor, não obstante estudioso de ambos, não explora os vínculos profundos entre eles. 
o autor, é uma lei de formação das leis, (Ibidem, v.7, § 515), observável, para nós, na mente humana. ${ }^{7}$ Como conseqüência, Peirce irá conjecturar sobre um monismo mente-matéria, em que a "matéria é uma forma de mente embotada por hábitos inveterados" (Ibidem), afirmação, a propósito, inteiramente extraída da Naturphilosophie de Schelling.

Esta é a raiz de seu Idealismo objetivo, que preconiza a idéia de um universo cujo substrato último é eidético, rompendo, assim, com doutrinas, segundo o autor, logicamente insustentáveis, situando-se, entre elas, o dualismo mente-matéria de cunho cartesiano e o monismo materialista que, se pode mostrar a partir de seu Pragmatismo, ${ }^{8}$ é equivalente a um mecanicismo determinista que não exibe suas credenciais fenomenológicas.

Em linguagem semiótica, estão sob evolução tanto o signo, em sua função representativa, como o Objeto, num continuum que não permite a pretensão de certeza absoluta e verdades finais. A este respeito, verdade é conceituada, no interior do sistema peirceano, como o fim para onde tende indefinidamente a representação da comunidade de investigação, numa fixação inabalável de seu sistema de crenças.

O Evolucionismo ontológico, completado pela Cosmologia peircea$\mathrm{na}^{9}$ que aqui seria impossível expor pela sua complexidade, a par de uma familiar e aceitável idéia de evolução histórica dos signos, é que proporciona o total e profundo entendimento de um conceito que tem criado polêmica entre os comentaristas, a saber, o de Interpretante Final, ou seja, a significação última das representações sobre o Universo do Ser. Este tema, certamente fascinante como pesquisa, comporta apenas sua menção no restrito espaço deste texto. Enquanto isso, nossas decisões têm de ser tomadas sob a incerteza que marca, por razões não tão-somente epistemológicas, mas e geneticamente ontológicas, nossas ações, nossa linguagem e nossas teorias.

\section{Conclusão}

À guisa de conclusão, cumpre realçar a cabal recusa do incognoscível por Peirce, estabelecendo seu vazio semântico, pois

\footnotetext{
7 Essa linha de argumento, na sua aparência insólita, é, todavia, conseqüência de uma construção realista que aproxima categorialmente sujeito e objeto, permitindo homologias muitas vezes acusadas, por alguns comentaristas, de antropomórficas.

8 Examinamos esse ponto em Ibri, 1992, cap.6.

9 Expusemos a Cosmologia de Peirce em Ibri, 1992, cap.5.
} 
nada sobre ele pode ser encontrado ou indicado. Conseqüentemente, nenhuma proposição pode a ele se referir e nada verdadeiro ou falso pode ser sobre ele predicado. Portanto, todas as referências a ele devem ser jogadas fora como algo supérfluo e sem sentido. (Peirce, 1931-1974, v.5, § 525.)

Além disso, segundo o autor, completando esta sua recusa, "o que está além da descoberta, seja direta ou específica ou indireta e geral, deve ser considerado não-existente" (Ibidem, v.6, § 101). Esta postura é conseqüência imediata de seu Pragmatismo, lido, também, em seu matiz ontológico.

Por esse viés, ou a potencialidade daquilo que é modalmente possível ou necessário se exibe como ato, caracterizando sua exteriorização fenomenológica e reduzindo-se à cognoscibilidade, ou sua realidade está comprometida por ser mera possibilidade que jamais adentra o teatro de reações da existência. Peirce, com esta posição, substitui os limites do conhecer pelos limites da certeza. Ao que é vedado à representação também cabe, somente, o silêncio apregoado por Wittgenstein.

Talvez tenhamos certeza absoluta, apenas, da inexorabilidade da morte. E, certamente, o seu preciso instante está escrito numa das infinitas faces do Acaso.

IBRI, I. A. About uncertainness. Trans/Form/Ação (São Paulo), v.23, p.97-104, 2000.

- ABSTRACT: This paper intends to expose elements of a Charles S. Peirce's epistemological doctrine, called by him Falibilism. The aim is to show how this doctrine emerge itself from the author's metaphysical theories, like his Evolutionism and categorical structure of Reality, forming a duet with his ontological conception of Chance. In fact, the Falibilism will be considered as the doctrine that is consequence of the Peirce's doble face indeterminism, i.e., at same time ontological and epistemological.

- KEYWORDS: Peirce; epistemology; metaphysics; chance.

\section{Referências bibliográficas}

ESPOSITO, J. Schelling's idealism and philosophy of nature. Lewisburg: Bucknell University Press, 1977.

. Evolutionary metaphysics: the development of Peirce's theory of categories. Athens: Ohio University Press, 1980. 
GRAYBOSH, A. J. Abduction, justification and realism. In: MOORE, E. (Ed.) Charles $S$. Peirce and the philosophy of science. Tuscaloosa: University of Alabama Press, 1993.

PEIRCE, C. S. Collected Papers of Charles Sanders Peirce. HARTSHORNE, C., WEISS, P., BURKS, A. (Ed.) Cambridge: Harvard University Press, 1931-1974. 8v

IBRI, I. A. Kósmos Noétos: a arquitetura metafísica de Charles S. Peirce. São Paulo: Perspectiva, 1992.

JOHANSON, A. E. Peirce and Wittgenstein's On Certainty. In: DEBROCK, G., HULSWIT, M. (Ed.) Living doubt: essays concerning the epistemology of Charles Sanders Peirce. Dordrecht: Kluwer Academic Publishers, 1994. 